\title{
Towards an Understanding of the Mutual Solubilities of Water and Hydrophobic Ionic Liquids in the Presence of Salts: The Anion Effect
}

\author{
Luciana I. N Tomé, ${ }^{\dagger}$ Fátima R. Varanda, ${ }^{\dagger}$ Mara G. Freire, ${ }^{\dagger, \dagger}$ Isabel M. Marrucho, ${ }^{\dagger, \dagger}$ and \\ João A. P. Coutinho*, \\ CICECO, Departamento de Química, Universidade de Aveiro, 3810-193 Aveiro, Portugal and Instituto de \\ Tecnologia Química e Biológica, ITQB2, Universidade Nova de Lisboa, Av. República, Apartado 127, \\ 2780-901 Oeiras, Portugal
}

Received: November 18, 2008; Revised Manuscript Received: December 24, 2008

\begin{abstract}
The understanding of the specific interactions between salt ions and ionic liquids (ILs) in aqueous solutions is relevant in multiple applications. The influence of a series of anions on the solubility of 1-butyl-3methylimidazolium tricyanomethane in aqueous environment was here studied. This study aims at gathering further information to evaluate the recently proposed ${ }^{1,2}$ mechanisms of salting-in- and salting-out-inducing ions in aqueous solutions of ILs and to provide insights at the molecular-level on the phenomena occurring in these systems. The observed effect of the inorganic species on the aqueous solubility of the ionic liquid qualitatively follows the Hofmeister series, and it is dependent on the nature and concentration of the anions. The liquid-liquid equilibrium data and ${ }^{1} \mathrm{H}$ NMR results here reported support a model according to which salting-in- and salting-out-inducing ions operate by essentially different mechanisms. While salting-out is an entropically driven effect resulting from the formation of hydration complexes and the increase of the surface tension of cavity formation, the salting-in phenomena is a consequence of the direct binding of the ions to the hydrophobic moieties of the IL. Further evidence here obtained suggests that the interactions of the inorganic ions are not only established with the cation of the IL, but also with the anion, with the observed solubility effect the result of a balance between those two types of interactions.
\end{abstract}

\section{Introduction}

Ionic Liquids (ILs) are commonly defined as organic salts melting at temperatures below $100{ }^{\circ} \mathrm{C}$, typically resulting from combinations of organic cations and various anions. ${ }^{3}$ This ionic nature confers them attractive properties such as negligible vapor pressure, ${ }^{4}$ large liquidus range, and good solvation ability ${ }^{5}$ and offers the possibility of finely tuning their polarities, viscosities, and hydrophobicities by introducing changes in the chemical structures of their constituent ions. ${ }^{6,7}$ With these unique features, it is not surprising that in the last several years ILs have gained a lot of attention in chemical and industrial research and are nowadays suggested as interesting alternatives for volatile and toxic organic solvents in numerous and diverse fields. ${ }^{8}$ Among the various appealing applications, the use of ILs as solvents in liquid-liquid extraction processes has recently generated a great deal of excitement and seems to be particularly promissory. ${ }^{9,10}$ In fact, the replacement of conventional organic solvents by ILs as extractors offers not only environmental advantages-energy savings in the separation of the extracted product from the IL due to the low vapor pressure of the latest and its potential recoverability for reuse $\mathrm{e}^{11}$ - but also the possibility of improving selective separation processes by customizing and manipulating the properties of the liquid through the modification of the anions and cations that compose them. As far as this aspect is concerned, the solvation ability of the IL and its miscibility with other solvents present in the extraction media can be dramatically altered, enabling the optimization of the efficiency of the

* Corresponding author phone: +351-234-370200; fax: +351-234370084; e-mail address: jcoutinho@ua.pt.

${ }^{\dagger}$ Universidade de Aveiro.

* Universidade Nova de Lisboa. recovery. An increasing number of publications describing the employment of ILs with low solubility in water as biphasic extraction media have actually been published in the past few years, ${ }^{12-14}$ and encouraging results for the recovery of acetone, ethanol, and butanol from fermentation broths and for the removal of organic contaminants from aqueous waste streams have been reported. ${ }^{13,14}$

For the correct design, optimization, and operation of extraction processes from aqueous media, a detailed understanding of the phase behavior of water and ILs is of utmost importance. Although some recent studies ${ }^{15-19}$ have provided liquid-liquid equilibrium data for IL/water systems, there is still a lack of information indispensible to improve the efficiency of the recoveries, especially as far as systems involving aqueous phases of biological media, usually containing salts, sugars, and fermentation metabolites, are concerned. In fact, in spite of the noticeable advantages of the use of ILs in the recovery of solutes or harmful substances from fermentation media and natural resources, there are still difficulties that might arise, sometimes compromising the success of the extraction or giving rise to undesirable environmental issues. Indeed, as focused in previous works, ${ }^{15-17}$ even those ILs considered hydrophobic present a significant solubility in water, leading to water contamination problems. In a recent publication from our work group ${ }^{1}$ it was shown that the addition of salts to the media can have a deep influence on the water-IL mutual solubilities, determining salting-in and salting-out effects in an extension related to the nature and concentration of the added salt. Consequently, as discussed in that work, one approach to overcome the difficulties mentioned above would be the promotion of salting-out effects by means of the addition of an adequate salt in a convenient concentration. It is therefore essential to further explore this 
subject towards the full understanding of the effect of the salt on the mutual solubilities of water and ionic liquids.

A deep knowledge of the behavior of water/IL systems in the presence of salts will not be achieved unless the underlying molecular-level mechanisms are understood in detail. Specific ion effects are ubiquitous and relevant in a wide range of chemical and biological fields and follow a recurring trend known as the Hofmeister series. ${ }^{20}$ This behavior, first noted on the ability of salts to precipitate certain proteins from an aqueous solution, ${ }^{21}$ is actually recognized as a general phenomenon present in a variety of aqueous processes ranging from enzymatic activity to colloidal assembly and polymer or protein folding. ${ }^{22-26}$ In investigations carried out recently in our work group,${ }^{1}$ it was observed that the sequence of the effect of salts on water-imidazolium-based IL mutual solubilities also qualitatively follows the Hofmeister series.

Although the rank of the relative influence of ions on the physical behavior of aqueous systems is well established, the molecular description of the underlying mechanism is far from being definitely elucidated and consensual, in spite of the several attempts developed throughout the years..$^{20,27-31}$ The explanation originally proposed and accepted for more than 100 years was based on the ability of a particular ion to alter the hydrogenbond networks of water. ${ }^{28,32-34}$ Some ions, known as "kosmotropes", were believed to be "water structure makers" and would thus give rise to salting-out effects, tending to precipitate proteins and prevent unfolding. Others, referred to as "chaotropes", would be "water structure breakers", originating salting-in effects and destabilizing folded macromolecules. For some authors, there is little doubt that the main cause of the effect is how bulk water structure is affected by the ion. In a series of thermodynamic studies on the behavior of 1-propanol in mixed solvents of aqueous sodium-salt solutions, Koga et al. ${ }^{35-37}$ related the effect of each salt to its own unique way of modifying the molecular organization of water, although recognizing that this single explanation can not account on its own for the complexity of the phenomenon. The structure maker/breaker classical dogma has lately been severely questioned in face of new experimental evidence obtained in the past few years ${ }^{27-29}$ that indicate that the ions have little effect on the overall hydrogen-bonding of water in bulk solution. Instead, newer theories emphasizing the significant role of dispersion forces and involving the relative polarizabilities of the ions and the specific ion binding have been proposed. ${ }^{38,39}$ One of the most consistent theories was suggested by Zhang et al. ${ }^{31,40,41}$ when probing for a general ion/water/polymer interaction mechanism to explain the effects of a series of sodium salts on the lower critical solution temperature (LCST) of poly( $\mathrm{N}$-isopropylacrylamide), PNIPAM. The authors claim that the Hofmeister effects of salts on macromolecules solubilities must depend on direct interactions of the ions with the macromolecules and with water molecules in the first hydration shell of the macromolecules.

Long-held classical ideas about changes in bulk water structure are progressively being overturned as new data flurries. Nevertheless, despite the fragmentary opinions among the scientific community and the lack of an universal molecular picture, it seems to be undoubtfully consensual that further research on this matter is mandatory since, after all, the Hofmeister series has become a fundamental framework with which many types of biological systems involving saline solutions are studied.

The imidazolium ion is commonly considered for extraction purposes since, when combined with adequate anions, the immiscibility of the resulting IL with water represents an extra

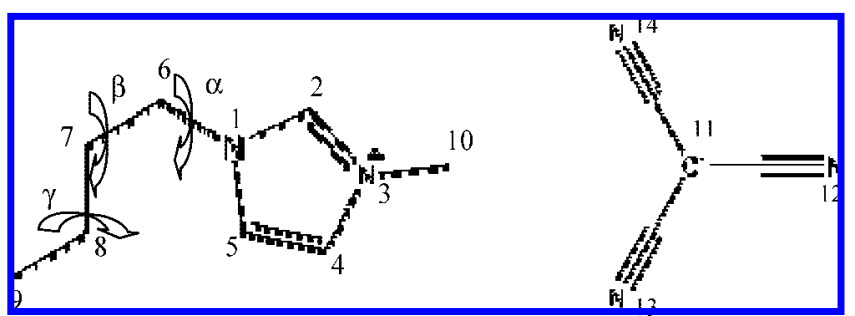

Figure 1. Chemical structure of the ions constituting the IL used in this work and correspondent atom numbering.

advantageous property when dealing with the recovery of products from aqueous environments..$^{17}$ In a previous study, ${ }^{1}$ the liquid-liquid equilibrium behavior of ternary systems composed of water, organic and inorganic salts, and a strongly hydrophobic ionic liquid, 1-buthyl-3-methylimidazolium bis(trifluoromethylsulfonyl)imide, $\left[\mathrm{C}_{4} \mathrm{mim}\right]\left[\mathrm{Tf}_{2} \mathrm{~N}\right]$, was explored. In the current work the influence of five sodium salts $-\mathrm{NaCl}$, $\mathrm{NaSCN}, \mathrm{NaNO}_{3}, \mathrm{Na}_{2} \mathrm{SO}_{4}$, and $\mathrm{Na}_{2} \mathrm{CO}_{3}-$ on the phase behavior of aqueous solutions of 1-buthyl-3-methylimidazolium tricyanomethane, $\left[\mathrm{C}_{4} \mathrm{mim}\right]\left[\mathrm{C}\left(\mathrm{CN}_{3}\right)\right]$, was investigated. For that purpose, the liquid-liquid phase diagrams of IL + water + inorganic salt were measured by turbidimetry, and the magnitude of the observed salting-in/salting-out effects through the IL was evaluated. By selecting sodium salts, we intend to individualize the effect of the nature and concentration of a series of anions on the liquid-liquid equilibria under study. It is well-known that the Hofmeister series behavior is generally more pronounced for anions than for cations,${ }^{20}$ the first are more polarizable and strongly hydrated, consequently promoting more pronounced salting-in/salting-out effects.

To get further insight of the molecular mechanisms that operate in these systems, spectroscopic NMR studies were also carried out. In combination with the phase equilibria experimental data obtained, the NMR results were used to discuss the different approaches to the molecular-level explanation of the Hofmeister series and interpret them in terms of the specific interactions of the salt with water and with the IL.

\section{Experimental Section}

Materials. The IL $\left[\mathrm{C}_{4} \mathrm{mim}\right]\left[\mathrm{C}(\mathrm{CN})_{3}\right]$ employed in the experiments reported was supplied by Merck with mass fraction purity $>99 \%$ and was used as received without further purification. Its purity was checked by ${ }^{1} \mathrm{H}$ and ${ }^{13} \mathrm{C}$ NMR spectra interpretation. The chemical structure of the ionic liquid and the correspondent atom numbering is depicted in Figure 1. The water used for the preparation of the saline solutions was doubledistilled, passed by a reverse osmosis system, and further treated with a Milli-Q plus 185 water purification apparatus. It has a resistivity of $18.2 \mathrm{M} \Omega \mathrm{cm}$, a TOC smaller than $5 \mu \mathrm{g} \mathrm{dm}^{-3}$, and it is free of particles greater than $0.22 \mu \mathrm{m}$. The inorganic salts, sodium chloride $(\mathrm{NaCl}$, Panreac, > $99.5 \mathrm{w} / \mathrm{w} \%)$, sodium thiocyanate (NaSCN, Fluka, $\geq 98.0 \mathrm{w} / \mathrm{w} \%$ ), sodium nitrate $\left(\mathrm{NaNO}_{3}\right.$, Himedia, $\left.>99.5 \mathrm{w} / \mathrm{w} \%\right)$, sodium sulfate $\left(\mathrm{Na}_{2} \mathrm{SO}_{4}\right.$, Panreac, $>99.0 \mathrm{w} / \mathrm{w} \%)$, and sodium carbonate $\left(\mathrm{Na}_{2} \mathrm{CO}_{3}\right.$, Carlo Erba, $>99.7 \mathrm{w} / \mathrm{w} \%$ ) were used as purchased without further purification. The deuterium oxide applied in ${ }^{1} \mathrm{H}$ NMR experiments was acquired from Aldrich with $>99.96 \% \mathrm{D}$ atom. The 3-(trimethylsilyl)propionic-2,2,3,3-d4 acid sodium salt (TSP) was obtained from Aldrich with $>98 \% \mathrm{D}$ atom.

Experimental Procedure. The phase diagrams for the binary and ternary systems $\left(\left[\mathrm{C}_{4} \mathrm{mim}\right]\left[\mathrm{C}(\mathrm{CN})_{3}\right]+\right.$ water + inorganic salt) were measured by turbidimetry. The salt solutions were gravimetrically prepared with an uncertainty of $\pm 10^{-4} \mathrm{~g}$, in the 
concentration range $[0-2.5] \mathrm{mol} \mathrm{kg} \mathrm{kg}^{-1}$. The onset of the liquid-liquid immiscibility (cloud point temperature) was determined by visual observation of the phase demixing (turbidity followed by phase separation). Approximately $0.5 \mathrm{~mL}$ of aqueous saline solutions and pure IL were introduced in sealed Pyrex-glass capillaries with a stirrer. The sealed capillaries were placed in a thermostatted bath where the samples were kept under continuous stirring during the whole experiment. Solutions presenting two phases at ambient temperature were heated into the homogeneous region and then slowly cooled until visual detection of phase demixing. The temperature at which the last sign of turbidity disappeared upon cooling was taken as the temperature of the liquid-liquid phase transition. For monophasic solutions at room temperature, the heating process was suppressed. The temperature was controlled with a calibrated Pt100 temperature sensor with an uncertainty of \pm $0.01 \mathrm{~K}$. Three measurements were carried for each solution. In the case of the water and IL-rich phase extremes of the binary system (water + IL), the data used was determined by analytical quantitative techniques in a previous work, ${ }^{16}$ and both methods are in satisfactory agreement.

For the NMR studies, a solution of $\left[\mathrm{C}_{4} \operatorname{mim}\right]\left[\mathrm{Tf}_{2} \mathrm{~N}\right]$ at approximately a mole fraction of $5 \times 10^{-3}$ or $3 \times 10^{-4}$ in $\mathrm{D}_{2} \mathrm{O}$ was prepared gravimetrically with an associated uncertainty of $\pm 10^{-4} \mathrm{~g}$, using TSP as a reference. These are concentrations below the IL saturation limit at 298 and $323 \mathrm{~K}$ and low enough to ensure completely dissociation in aqueous solution. The salt solutions were prepared gravimetrically in the $\mathrm{D}_{2} \mathrm{O}$-IL-TSP initial solution with salt molalities ranging from 0 to $1.0 \mathrm{~mol}$ $\mathrm{kg}^{-1}$. For each anion effect analysis, the IL is at exactly the same concentration as the pure IL- $\mathrm{D}_{2} \mathrm{O}$-TSP solution employed to determine the chemical shifts deviations. Care was taken in order to avoid contamination of the solutions with moisture. The ${ }^{1} \mathrm{H}$ NMR spectra were recorded using a Bruker Avance 300 at $300.13 \mathrm{MHz}$ using $\mathrm{D}_{2} \mathrm{O}$ as solvent and TSP as internal reference.

\section{Results}

Liquid-Liquid Equilibrium (LLE). In a first set of experiments, temperature-composition phase diagrams of the binary mixture $\left(\left[\mathrm{C}_{4} \mathrm{mim}\right]\left[\mathrm{C}(\mathrm{CN})_{3}\right]+\mathrm{H}_{2} \mathrm{O}\right)$ in the presence of three sodium salts $-\mathrm{NO}_{3}{ }^{-}, \mathrm{Cl}^{-}$, and $\mathrm{SO}_{4}{ }^{2-}$ - at two or three fixed concentrations were measured. The corresponding data are plotted in Figure 2. Both decreases (salting-out) and increases (salting-in) of the mutual solubilities of IL/water are observed. $\mathrm{NO}_{3}{ }^{-}$is the sodium-based salt that induces the most pronounced salting-in effect of the IL from the aqueous phase, and more evident if present in a concentration of $1 \mathrm{~mol} \mathrm{~kg}^{-1}$. The solubilities in the aqueous-rich and IL-rich phases seem to be affected in a similar way. At a lower $\mathrm{NaNO}_{3}$ molality, $m=0.1$ mol kg-1, the salting-in effect becomes less significant, and there is practically no shift relative to the cloud-point temperature of the (water + IL) binary system along the entire phase transition curve. The same type of concentration effect is observed for $\mathrm{NaCl}$, but inversely to $\mathrm{NaNO}_{3}$, this salt promotes a relatively pronounced decrease of the mutual solubilities of IL and water when its concentration in the $\left(\mathrm{H}_{2} \mathrm{O}+\right.$ inorganic salt $)$ solution is $1 \mathrm{~mol} \mathrm{~kg}^{-1}$. In contrast, $\mathrm{Na}_{2} \mathrm{SO}_{4}$ induces a strong salting-out effect at all the molalities considered. It is actually the salt that has the strongest effect on decreasing the mutual solubilities. Moreover, the shape of the cloud-point temperature for the ternary systems involving this anion is quite different from the others. In fact, it is quite obvious that the solubilities on the IL-rich phase are more affected by the presence of $\mathrm{Na}_{2} \mathrm{SO}_{4}$ than on the water-rich phase. This is already clear for $m=0.5 \mathrm{~mol}$ $\mathrm{kg}^{-1}$ and becomes even more evident as the molality of the salt increases. It is worth to note that this type of solubility behavior has recently been reported for aqueous solutions of the IL 1-buthyl-3-methylimidazolium tetrafluoroborate, $\left[\mathrm{C}_{4} \mathrm{mim}\right]\left[\mathrm{BF}_{4}\right]{ }^{42}$ To better evaluate the trend of the salting-in/ salting-out effects, the results obtained for the liquid-liquid phase diagrams of the (IL + water + inorganic salt) solutions at fixed $1 \mathrm{~mol} \mathrm{~kg}^{-1}$ salt concentrations are represented in Figure $2 b$. The graph shows that the effect of the anions on the IL solubility in water decrease is ordered as follows: $\mathrm{NO}_{3}{ }^{-}<\mathrm{Cl}^{-}$ $<\mathrm{SO}_{4}{ }^{2-}$.

In a second set of experiments, the effect of anion type and concentration on the critical point change of the binary system (IL $+\mathrm{H}_{2} \mathrm{O}$ ) was further evaluated. For this purpose, five sodium species- $\mathrm{Na}_{2} \mathrm{SO}_{4}, \mathrm{Na}_{2} \mathrm{CO}_{3}, \mathrm{NaNO}_{3}, \mathrm{NaSCN}$, and $\mathrm{NaCl}$-were added to aqueous solutions of IL with a near-critical composition $\left(w \mathrm{c}_{\mathrm{IL}}=0.38\right.$ for $\left.T \mathrm{c}=326 \mathrm{~K}\right)$. Figure 3 shows the results obtained for the cloud-point temperatures of $\left(\left[\mathrm{C}_{4} \mathrm{mim}\right]\left[\mathrm{C}(\mathrm{CN})_{3}\right]\right.$ $+\mathrm{H}_{2} \mathrm{O}+$ inorganic salt) mixtures as a function of the molality of the salt. By performing this more detailed study on the anion type and concentration effects than the one developed in the first set of experiments through the use of a larger series of sodium salts at several different concentrations, we intend to cover a wider range of solubility effects and get a more complete picture of the behavior of the (IL + water) system in the presence of diverse sodium-based anions. For the $\mathrm{SO}_{4}{ }^{2-}$ and $\mathrm{CO}_{3}{ }^{2-}$ anions, significant positive shifts in the transition temperature are observed, corresponding to salting-out effects. From the results obtained it is rather difficult to infer which salt promotes the strongest effect. The $\mathrm{NaCl}$ also induces a decrease of the IL solubility in water, although less pronounced. The solubility of $\left[\mathrm{C}_{4} \mathrm{mim}\right]\left[\mathrm{C}(\mathrm{CN})_{3}\right]$ in the aqueous phase containing these species shows a linear dependence on salt concentration, and the temperature shifts are actually nearly proportional to the salt molality increase. An IL salting-in effect is promoted by $\mathrm{NaSCN}$, in a similar linear pattern. $\mathrm{NaNO}_{3}$ behaves quite differently, inducing a nonlinear concentration effect on the IL solubility. Indeed, at low salt concentration, negative shifts are observed in the transition temperature, whereas at higher molality regions salting-out effects appear. It is worth to note, however, that these are only slightly pronounced in the entire range of concentration. An identical solubility effect was observed in aqueous sodium chloride solutions for $\left[\mathrm{C}_{4} \mathrm{mim}\right]\left[\mathrm{Tf}_{2} \mathrm{~N}\right] .^{1,2}$

To guarantee that the observed effects are a result of the salt concentration and not of a change on the $\mathrm{pH}$ of the aqueous media due to the salts acid/basic character the effect of the $\mathrm{pH}$ on the $\left[\mathrm{C}_{4} \mathrm{mim}\right]\left[\mathrm{C}\left(\mathrm{CN}_{3}\right)\right]$ solubility in water was evaluated. For that purpose a third set of experiments was performed by measuring the phase diagrams of $(\mathrm{HCl} / \mathrm{NaOH}+$ water + IL) mixtures, with $\mathrm{pH}$ values ranging from 1 to 13 . As can be seen from the results depicted in Figure 4, the $\mathrm{pH}$ influence on the solubility of $\left[\mathrm{C}_{4} \mathrm{mim}\right]\left[\mathrm{C}\left(\mathrm{CN}_{3}\right)\right]$ in water is negligible when compared to the effect of the added salts. Consequently, the observed results for the solubility behavior are not promoted by changes in the $\mathrm{pH}$ of the solutions, thus the $\mathrm{pH}$ influence will be neglected in the discussion developed throughout this work.

Spectroscopic Studies. ${ }^{1} \mathrm{H}$ RMN spectra were obtained at $T$ $=298.15 \mathrm{~K}$ for $\left[\mathrm{C}_{4} \mathrm{mim}\right]\left[\mathrm{C}(\mathrm{CN})_{3}\right]$ aqueous $\left(\mathrm{D}_{2} \mathrm{O}\right)$ sodium solutions of $\mathrm{Cl}^{-}, \mathrm{SO}_{4}{ }^{2-}$, and $\mathrm{SCN}^{-}$, in the salt concentration range from 0.0 to $1.0 \mathrm{~mol} \mathrm{~kg}{ }^{-1}$ and $w_{\mathrm{IL}}=0.07$. The chemical structure and atom numbering for the IL studied are shown in 


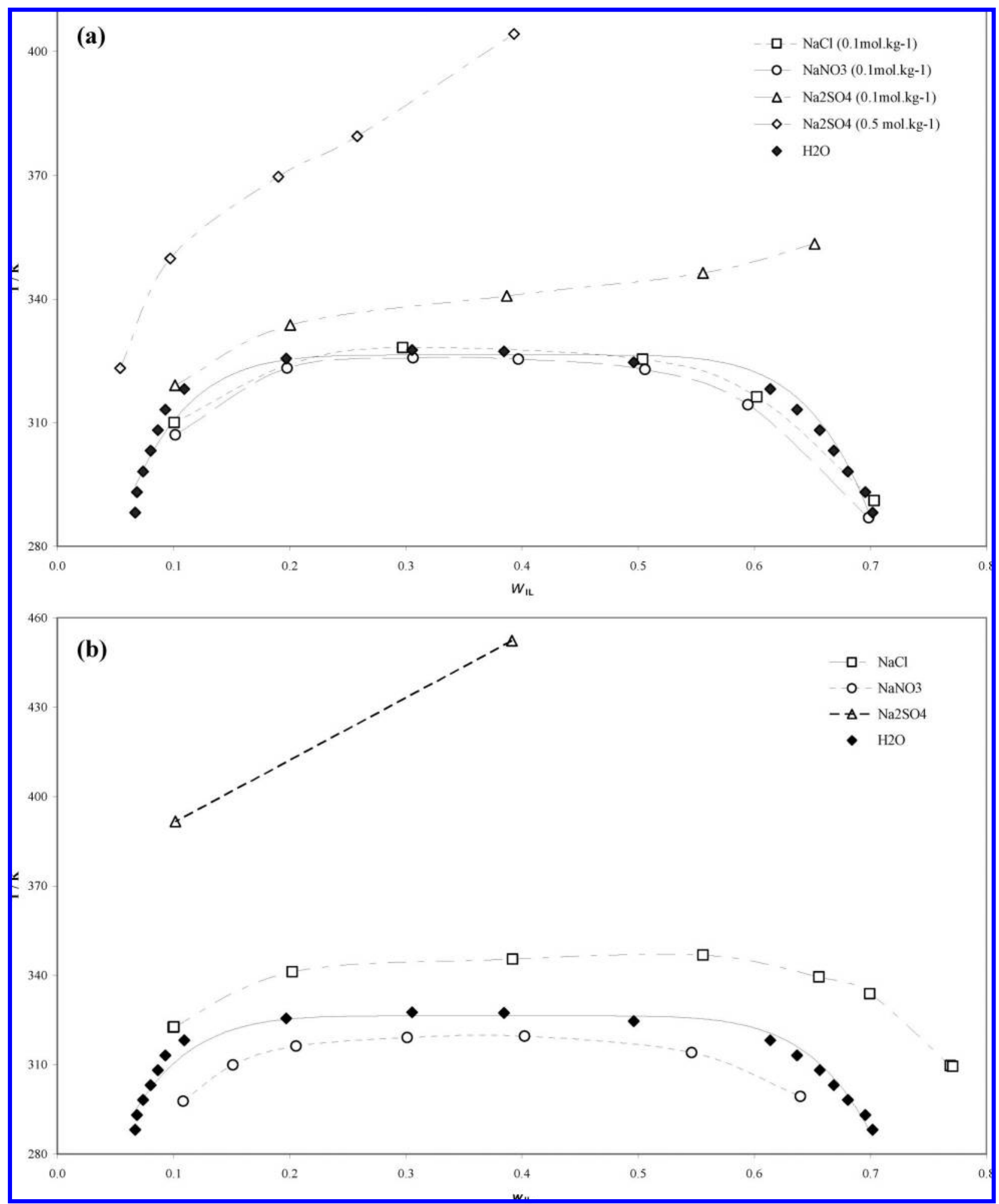

Figure 2. Temperature-composition phase diagrams of $\left(\left[\mathrm{C}_{4} \mathrm{mim}\right]\left[\mathrm{C}(\mathrm{CN})_{3}\right]+\mathrm{H}_{2} \mathrm{O}+\right.$ inorganic salt $)$ as a function of the weight fraction $\left(w_{\mathrm{IL}}\right)$ of $\mathrm{IL}$ in the ternary system (a) at low salt concentrations and (b) for salt concentration $m=1 \mathrm{~mol} \mathrm{~kg}^{-1}$. All solid lines were drawn as visual aids, except for the binary system (IL + water), for which they were calculated using a scaled equation $\left(w_{\mathrm{IL}}=0.38, T \mathrm{c}=326 \mathrm{~K}\right){ }^{42}$

Figure 1. The chemical shift deviations for the protons of the IL cation are represented in Figures 5a, 6, and 7 as a function of salt molality and were determined from the difference between the chemical shifts of the saline aqueous solutions and the chemical shifts of the pure $\left[\mathrm{C}_{4} \mathrm{mim}\right]\left[\mathrm{C}(\mathrm{CN})_{3}\right]$ (cf. Supporting Information for more detailed data). The spectra studied were chosen to cover three distinct and representative cases of ions effects on the solubility of the IL: the two extreme salting-out-
$\left(\mathrm{SO}_{4}{ }^{2-}\right)$ and salting-in- $\left(\mathrm{SCN}^{-}\right)$inducing ions and the middle of the rank of the series $\left(\mathrm{Cl}^{-}\right)$. In the last case, an additional spectrum (Figure 5b) was obtained for the $w \mathrm{c}_{\mathrm{IL}}=0.38$ and $T \mathrm{c}$ $=323 \mathrm{~K}$, in order to explore the concentration effect of the IL.

\section{Discussion}

From the results presented in Figures 2 and 3, we can observe that the anions considered in this work promoted both salting- 


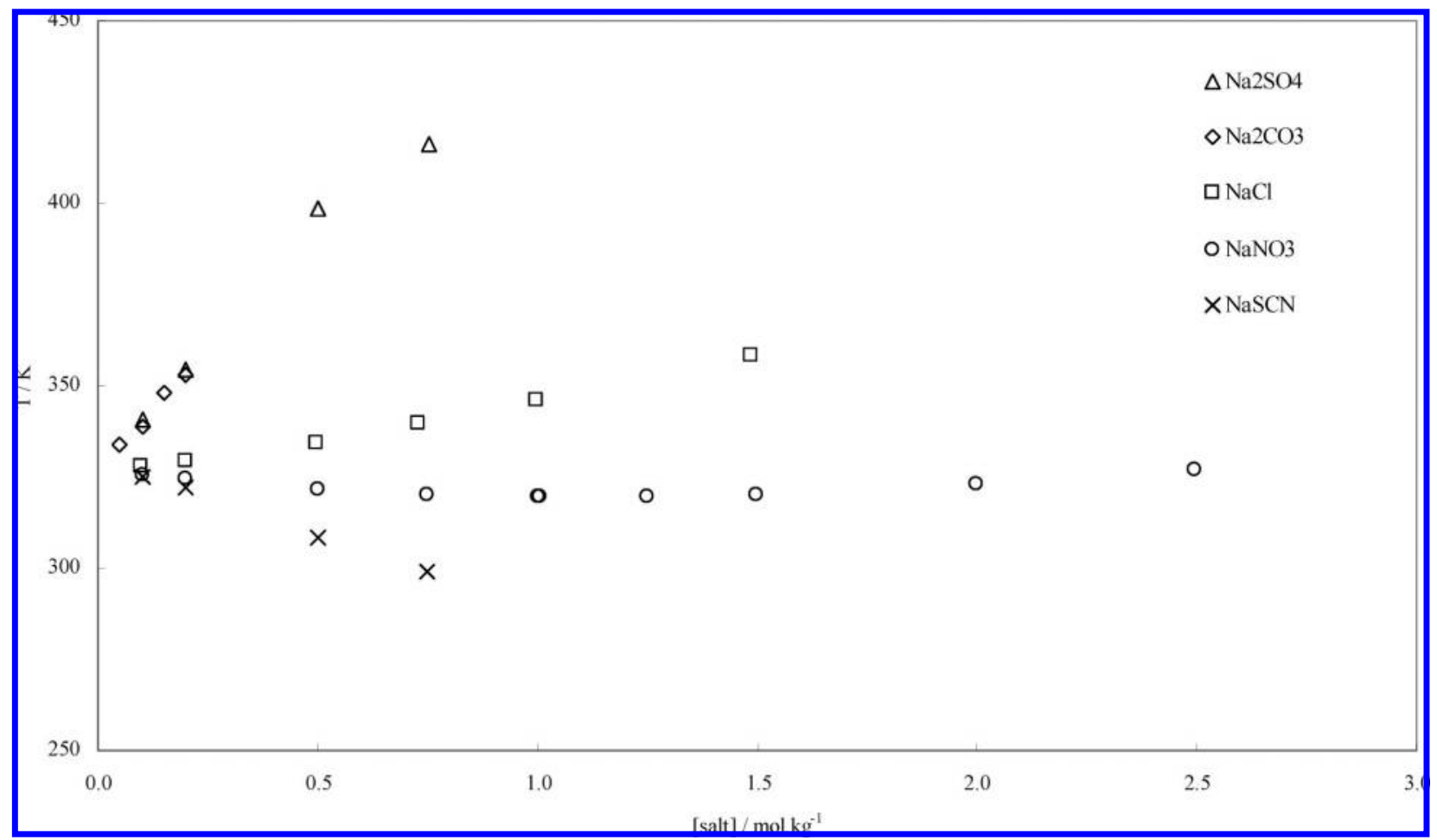

Figure 3. Plots of cloud-point temperature of ( $\mathrm{IL}+\mathrm{H}_{2} \mathrm{O}+$ salt) systems $\left(w \mathrm{c}_{\mathrm{IL}}=0.38\right)$ as a function of the molality of inorganic salt in the (IL $\left.+\mathrm{H}_{2} \mathrm{O}\right)$ solution.

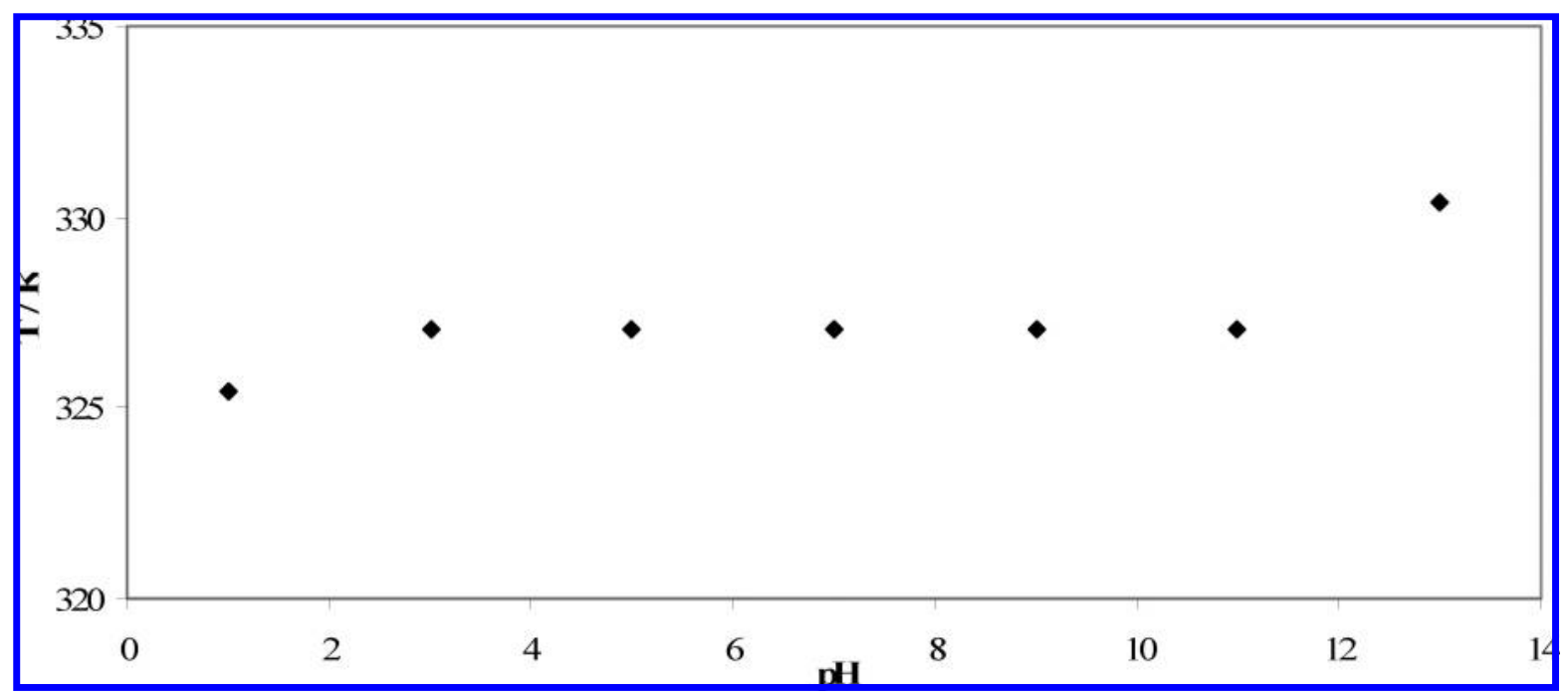

Figure 4. Plots of cloud-point temperature of $\left(\mathrm{IL}+\mathrm{H}_{2} \mathrm{O}\right)$ systems $\left(w \mathrm{c}_{\mathrm{IL}}=0.38\right)$ as a function of the $\mathrm{pH}$ of the solution.

in and salting-out effects, in a magnitude dependent on their nature and concentration. The strongest salting-out-inducing ions are $\mathrm{SO}_{4}{ }^{2-}$ and $\mathrm{CO}_{3}{ }^{2-}$ and, in general terms, the strength of this effect decreases in the order $\mathrm{SO}_{4}{ }^{2-} \cong \mathrm{CO}_{3}{ }^{2-}>\mathrm{Cl}^{-}>\mathrm{NO}_{3}{ }^{-}>$ $\mathrm{SCN}^{-}$, qualitatively following the Hofmeister series. ${ }^{20}$ The trend observed for the solubility of $\left[\mathrm{C}_{4} \mathrm{mim}\right]\left[\mathrm{C}(\mathrm{CN})_{3}\right]$ in aqueous salt solutions is actually analogous to that observed for other ILs $s^{1,42}$ and other charged molecules such as amino acids and proteins, although it is important to note that some of the inorganic anions here considered promote different effects when compared to aqueous solutions of other $\left[\mathrm{C}_{4} \mathrm{mim}\right]$-based ILs. This subject will be addressed in detail latter in this discussion.

Recent works concerning the effect of salts on the aqueous solubility of complex molecules ${ }^{37,43-46}$ are suggesting that watermediated interactions between hydrophobic solutes and salt ions are closely related to the extent of hydration of individual ions.
The association of high charge density ions with an hydrophobic solute is a highly unfavorable process, so they exclude themselves from the vicinity of the solute due to their preferential hydration (water-ion interactions stronger than water-water interactions), decreasing the solubility of the latest in water. In contrast, there is a strong association tendency of large and weakly hydrated ions (water-ion interactions weaker than water-water interactions) with hydrophobic solutes; consequently, they preferentially bind directly to the solute, promoting its stabilization in water and therefore a salting-in effect. A question that comes up in this context is if those solubility effects can or can not be directly correlated to the hydration strength of the different ions of the inorganic salts. ${ }^{42}$ To scrutinize this issue in a more quantitative perspective, we used one of the several thermodynamic parameters that have been applied to quantify the ion effects on the solute solubility 


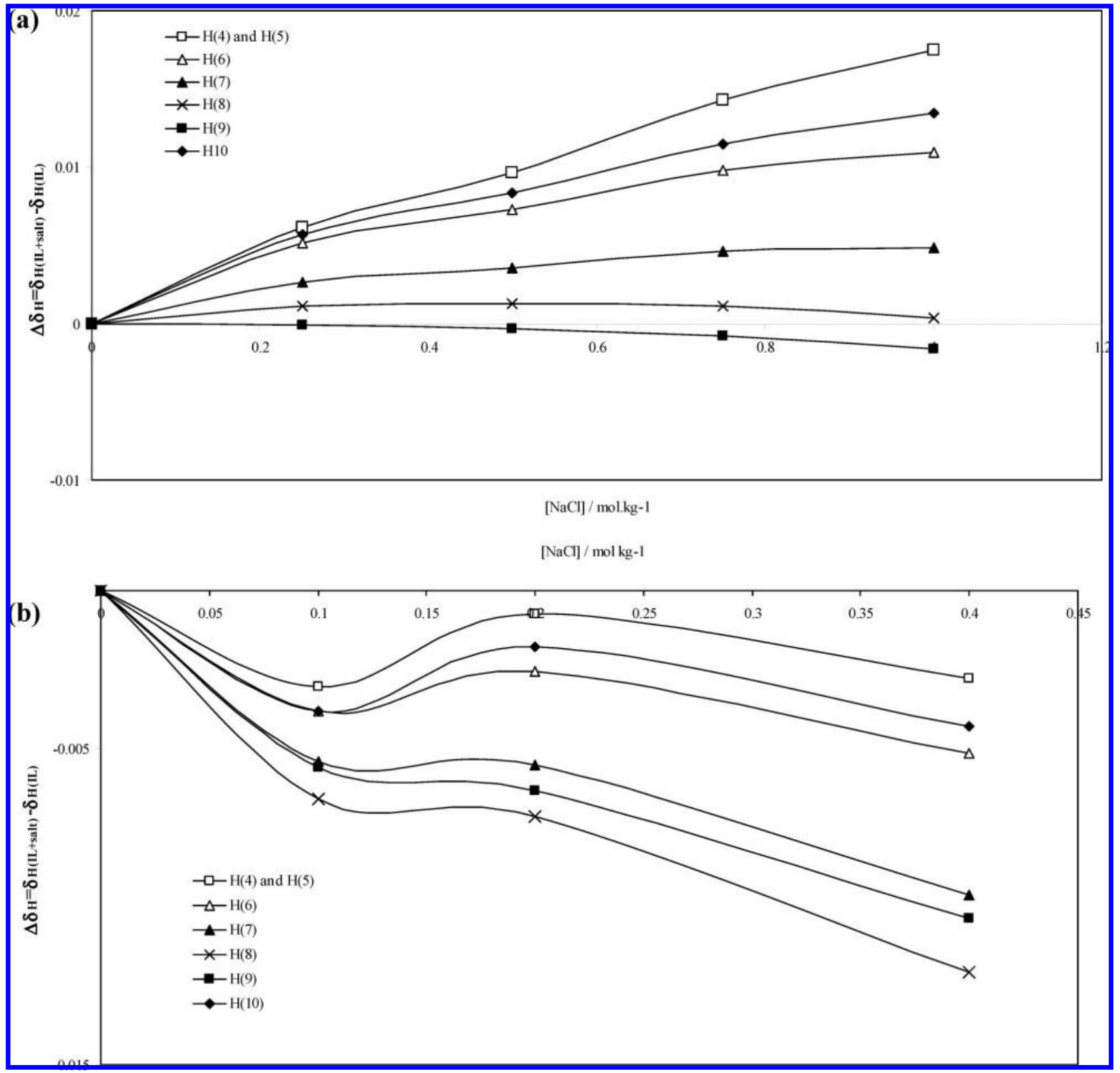

Figure 5. ${ }^{1} \mathrm{H}$ NMR chemical shifts deviations between the salt aqueous solutions and the pure $[\mathrm{bmim}]\left[\mathrm{C}\left(\mathrm{CN}_{3}\right)\right]$ as a function of $\mathrm{NaCl}$ molality (relative to TSP in $\mathrm{D}_{2} \mathrm{O}$ ) at (a) $T=298.15 \mathrm{~K}$ and $w_{\mathrm{IL}}=0.07$ and (b) $T=323 \mathrm{~K}$ and $w_{\mathrm{IL}}=0.38$.

in aqueous systems, the molar Gibbs energy of hydration, $\Delta_{\text {hyd }} G$. The values taken ${ }^{47}$ for $\Delta_{\text {hyd }} G$ of the anions composing the inorganic salts employed in this study are presented in Table 1. If the salting-out effect was caused solely by the different extent of hydration of the different anions, there would be a more pronounced difference between the salting-out-inducing effect of $\mathrm{SO}_{4}{ }^{2-}$ and $\mathrm{CO}_{3}{ }^{2-}$, since $\Delta_{\text {hyd }} G\left(\mathrm{CO}_{3}{ }^{2-}\right)$ is about half the value of $\Delta_{\text {hyd }} G\left(\mathrm{SO}_{4}{ }^{2-}\right)$. Likewise, since $\Delta_{\text {hyd }} G\left(\mathrm{NO}_{3}{ }^{-}\right)$and $\Delta_{\text {hyd }} G$ $\left(\mathrm{SCN}^{-}\right)$have relatively close values, there is no apparent justification for such a distinct inducing behavior of these two anions on the solubility of the IL. Although this is obviously only a rough argument, it is clear that the extent of hydration of the ions is not sufficient to give an adequate description of the mechanisms operating in these systems and that salting-in and salting-out effects are rather complex phenomena, resulting from the interplay of different types of interactions between the ions, the IL, and the solvent. An extra argument in support of this last statement comes from the results displayed in Figure 2. Indeed, the different shapes of the immiscibility envelopes for each system, particularly for $\mathrm{SO}_{4}{ }^{2-}$ at high concentrations, indicate that there must be other processes causing the demixing of the solution. It has been claimed ${ }^{42}$ that precipitation of the inorganic salt itself might be a reasonable explanation, but other factors are involved for sure. This salt precipitation could be a result of the $\mathrm{Na}_{2} \mathrm{SO}_{4}$ salting-out promotion by the IL itself (obviously one more salt competing in aqueous solution). There is thus the need to seek more complex and quantitative interpretations and to make use of theories that might help to quantify the salt effects on interactions with ILs.

One of the most interesting theories to understand the effect of salts on the aqueous solubility of molecules was proposed by Zhang et al. ${ }^{25}$ to describe the specific ion effects on the solubility of PNIPAM in water, and the theory was extended with success to the interpretation of $\left[\mathrm{C}_{4} \mathrm{mim}\right]\left[\mathrm{TF}_{2} \mathrm{~N}\right]$ solubility in aqueous salt solutions in a recent work by us. ${ }^{1}$ According to these works, the mechanism of action of salting-in- and saltingout-inducing ions on the solubility of ILs in aqueous salt solutions are fundamentally different and related to two major 


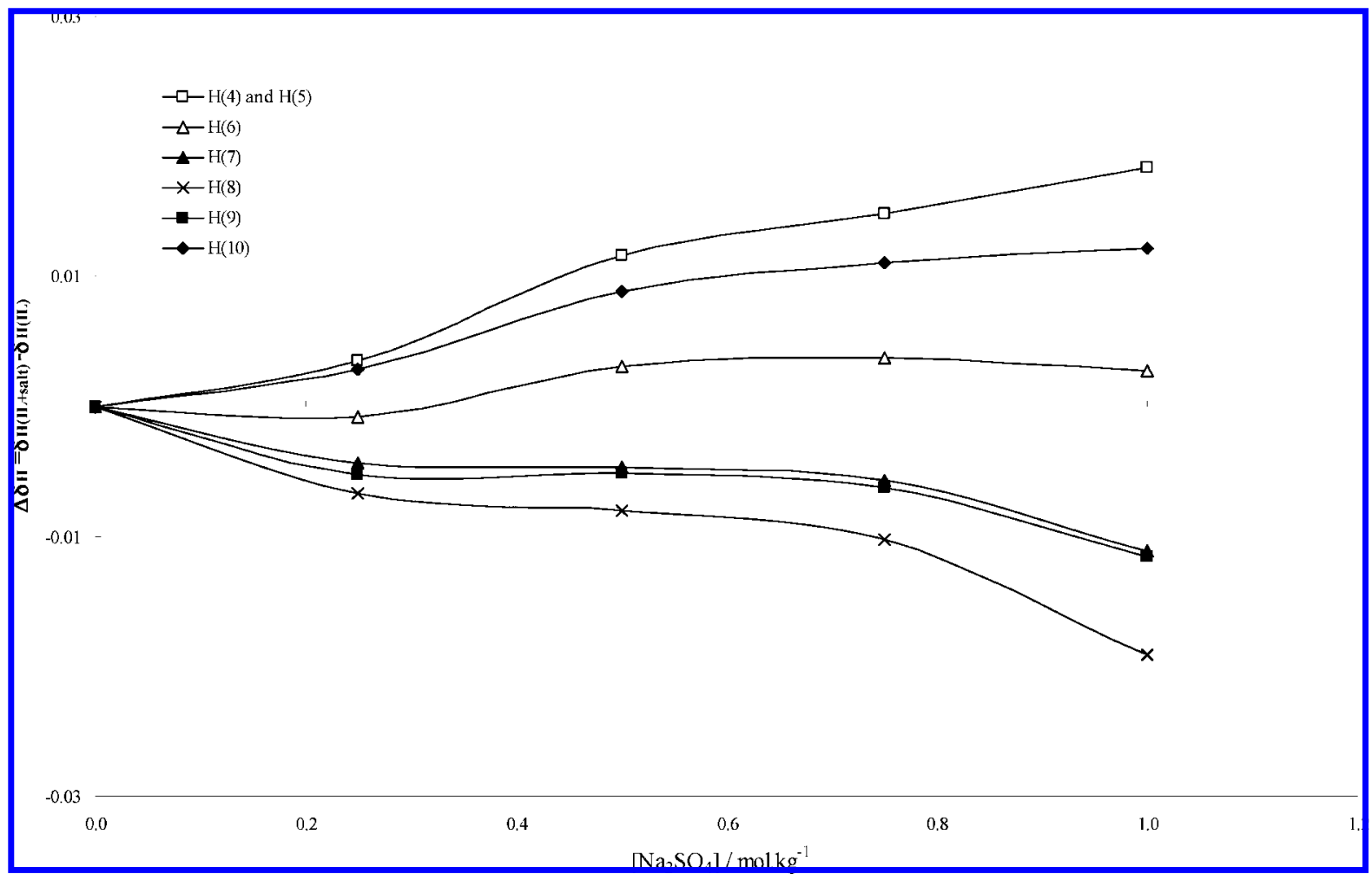

Figure 6. ${ }^{1} \mathrm{H}$ NMR chemical shifts deviations between the salt aqueous solutions and the pure $[$ bmim $]\left[\mathrm{C}\left(\mathrm{CN}_{3}\right)\right]$ as a function of $\mathrm{Na}_{2} \mathrm{SO}_{4}$ molality (relative to TSP in $\mathrm{D}_{2} \mathrm{O}$ ), at $T=298.15 \mathrm{~K}$ and $w_{\mathrm{IL}}=0.07$.

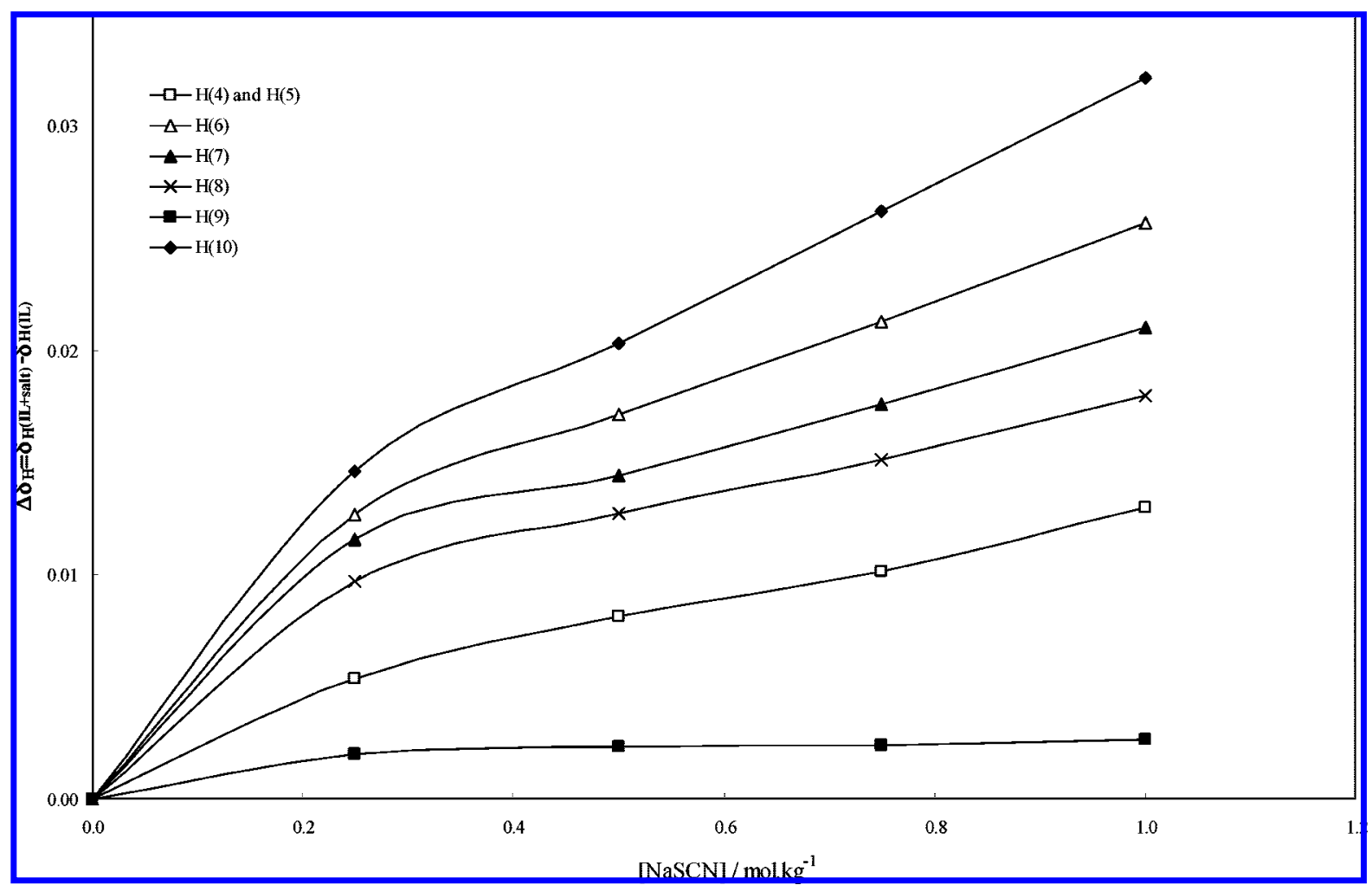

Figure 7. ${ }^{1} \mathrm{H}$ NMR chemical shifts deviations between the salt aqueous solutions and the pure $[\mathrm{bmim}]\left[\mathrm{C}\left(\mathrm{CN}_{3}\right)\right]$ as a function of NaSCN molality (relative to TSP in $\mathrm{D}_{2} \mathrm{O}$ ), $T=298.15 \mathrm{~K}$ and $w \mathrm{c}_{\mathrm{IL}}=0.07$.

specific ion effects: (i) a direct binding between the ions of low charge density and the hydrophobic moiety of the IL, promoting salting-in; (ii) an entropic effect originating salting-out, related to the formation of hydration complexes away from the solute hydrophobic moieties and to an increase on the surface tension of water and thus on the energy of cavity formation, due to the presence of high charge density ions. As shown below, this interpretation provides a good explanation for the experimental results reported on this work.

Following the approach of Zhang et al. ${ }^{25}$ the perturbation on the solubility of a solute caused by the addition of salts, at constant temperature, can be described by an equation consisting 


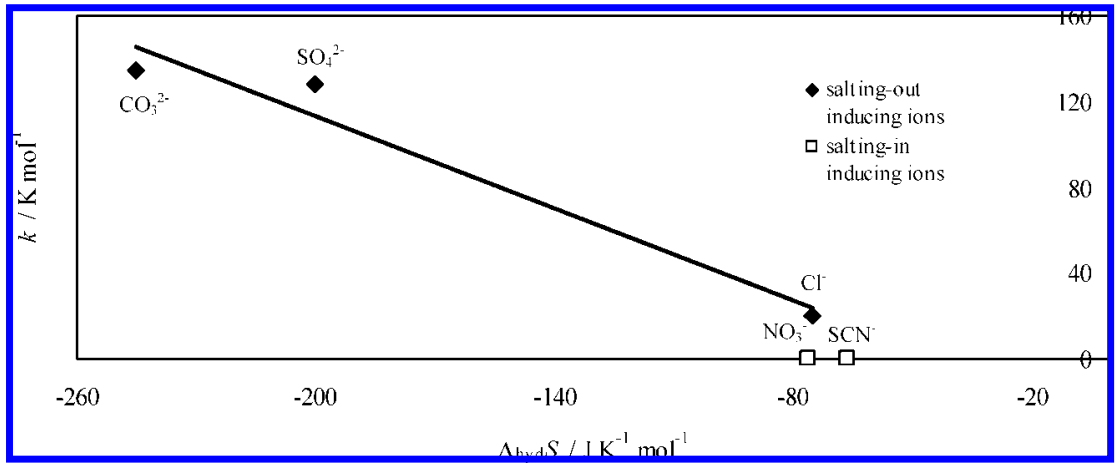

Figure 8. $k$ parameter from eq 1 as a function of the molar entropy of hydration $\left(\Delta_{\text {hyd }} S\right)$ of the anions.

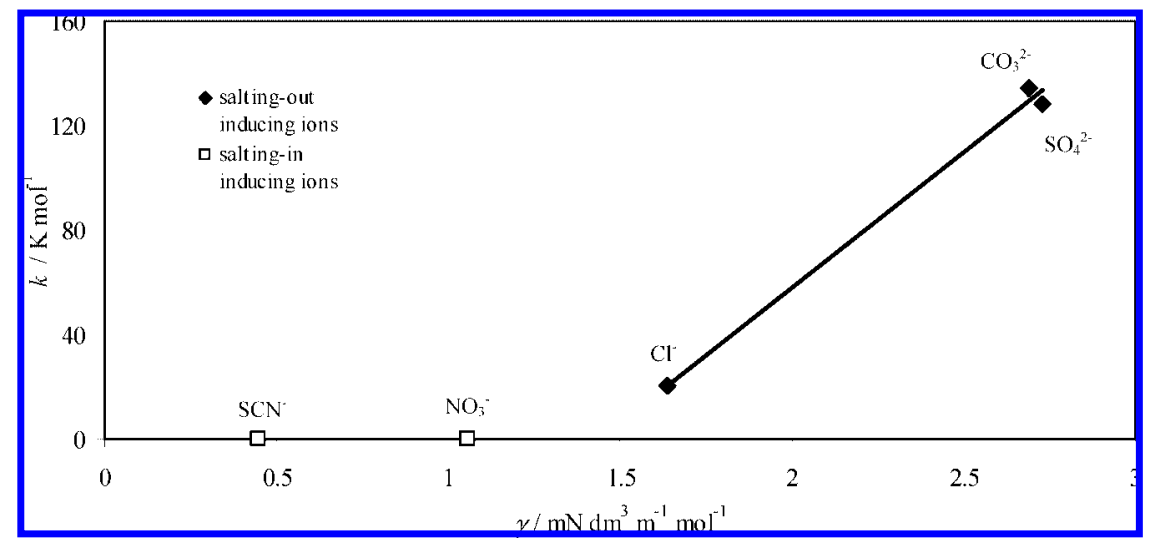

Figure 9. $k$ parameter from eq 1 as a function of the surface tension increment, $\gamma$, of the anions.

TABLE 1: Fitted Values for $k, K_{\mathrm{A}}$, and $\boldsymbol{B}_{\max }$ Obtained Using Equation 1 and Literature Data for Molar Entropy of Hydration, $\Delta_{\mathrm{hyd}} S,{ }^{47}$ and Molar Gibbs Energy of Hydration, $\Delta_{\mathrm{hyd}} G^{47}$ at 298.15 $\mathrm{K}$ and Surface Tension Increments, $\gamma,{ }^{48}$ for the Anions Studied in This Work

\begin{tabular}{|c|c|c|c|c|c|c|}
\hline anion & $k /\left(\mathrm{K} \cdot \mathrm{mol}\right.$ of $\left.\mathrm{salt}^{-1}\right)$ & $K_{\mathrm{A}} /\left(\mathrm{kg} \cdot \mathrm{mol}\right.$ of salt $\left.{ }^{-1}\right)$ & $B_{\max } /(\mathrm{K})$ & $\Delta_{\text {hyd }} \mathrm{S} /\left(\mathrm{J} \cdot \mathrm{K}^{-1} \cdot \mathrm{mol}^{-1}\right)$ & $\Delta_{\mathrm{hyd}} G /\left(\mathrm{kJ} \cdot \mathrm{mol}^{-1}\right)$ & $\gamma /\left(\mathrm{mN} \cdot \mathrm{dm}^{3} \cdot \mathrm{m}^{-1} \cdot \mathrm{mol}^{-1}\right)$ \\
\hline $\mathrm{SCN}^{-}$ & $1.5648 \times 10^{-8}$ & 0.0016 & -21763.8336 & -66 & -287 & 0.45 \\
\hline $\mathrm{NO}_{3}^{-}$ & $2.4810 \times 10^{-8}$ & 0.8461 & -15.4925 & -76 & -306 & 1.06 \\
\hline $\mathrm{SO}_{4}^{2-}$ & $1.2805 \times 10^{2}$ & & & -200 & -1090 & 2.73 \\
\hline $\mathrm{Cl}^{-}$ & $2.0148 \times 10^{1}$ & & & -75 & -347 & 1.64 \\
\hline
\end{tabular}

of a linear dependency on the salt concentration plus a term for the adsorption of the salting-in-inducing salts to the solute:

$$
T=T_{0}+k c+\left[B_{\max } K_{A} c /\left(1+K_{A} c\right)\right]
$$

where $T_{0}$ is the cloud-point temperature of the (IL + water) system in the absence of salt; $c$ is the concentration of salt in molality; and $K_{A}, B_{\max }$, and $k$ are adjustable parameters describing the phenomena that affect the solute solubility. The constant $k$ is, in fact, a measure of the ion effects observed and is suggested to be related to other thermodynamic parameters, such as surface tension, $\gamma$, and molar entropy of hydration of the ions, $\Delta_{\text {hyd }} S$.

To understand the behavior of the $\left(\left[\mathrm{C}_{4} \mathrm{mim}\right]\left[\mathrm{C}(\mathrm{CN})_{3}\right]+\right.$ water + inorganic salt) system under study, eq 1 was applied to the data measured in this work. It is worth to note that the last term was only used for salting-in-inducing ions as Zhang et al. suggested. ${ }^{25}$ The results for the fitted parameters are displayed in Table 1 , as well as the values for $\Delta_{\text {hyd }} S^{47}$ and $\gamma^{48}$ taken from literature.

The plot of the constant $k$ as a function of $\Delta_{\text {hyd }} S$ of the anions (Figure 8) shows a rather good correlation between these two quantities for high charge density ions. The proportionality observed indicates that the mechanism of phase transition by which salting-out-inducing ions operate in $\left(\left[\mathrm{C}_{4} \mathrm{mim}\right]\left[\mathrm{C}(\mathrm{CN})_{3}\right]\right.$ + water) mixtures is entropically driven as suggested before not only for polymer systems ${ }^{25,31,41,45}$ but also for aqueous solutions of ILs. ${ }^{1,15,16}$ No such trend is observed for low charge salting-in-inducing ions. This suggests that highly charged density ions are capable of weakening water-IL interactions, causing the dehydration of the solute by forming water-ion hydration complexes.

The dependence of $k$ on the surface tension increment induced by each anion is represented in Figure 9. Again, there is a direct correlation between the salting-out effect observed and the surface tension increment for high charge density ions, and no detectable correlation for low charge density ions is found. This indicates that the former raise the surface tension of the water-IL interface, increasing the cost of the hydration of the solute.

The dependence of the magnitude of the salting-out effect observed, as measured by $k$, on the molar entropy of hydration and on the surface tension increment of the ions strongly suggests that step (ii) is the molecular-level basis for the saltingout mechanism. However, it is not possible to separate the two salting-out-inducing effects-formation of hydration complexes ion-water and energy of cavity formation-since both are 
coupled in eq 1. Therefore, it is still difficult to infer the specificity of the contribution of the modification of the interfacial tension of the cavity formed for the mechanism of salting-out, as stated previously. ${ }^{1}$

The Zhang et al. ${ }^{25}$ approach applied above to the data measured in this work shows that salting-out- and salting-ininducing ions act through separate mechanisms, although it does not provide much evidence for the mechanism by which the last ions operate. To get further insight onto the molecular nature of the ions effects on the solubility of the IL in water, particularly as far as the salting-in-inducing phenomenon is concerned (step (i) of the mechanism), we appealed in this work to ${ }^{1} \mathrm{H}$ NMR spectroscopic evidence, as discussed below.

Complementary and valuable evidence for the microscopic interactions determining salting-in and salting-out effects, in particular for the direct ion binding to the IL cation, can actually be provided by alternative experimental methods, such as NMR. ${ }^{2}$ Contrarily to what had been suggested before by Zhang et al. ${ }^{25}$ for polymers, our recent results ${ }^{2}$ show that the salting-in effect lies not on the binding of the ions to the polar or charged parts of the IL but on their direct interaction to its hydrophobic moiety. When such interaction is not observed, the phenomenon of salting-out takes place, since the binding with the water molecules is preferential. In fact, as shown in Figures 6 and 7, for both $\mathrm{SO}_{4}{ }^{2-}$ and $\mathrm{SCN}^{-}$sodium-based salts, positive chemical shifts deviations, resulting from attractive interactions between the salt ions and the solute, are observed for the protons of the ring and of carbons 6 and $10[\mathrm{H}(4), \mathrm{H}(5), \mathrm{H}(6)$, and $\mathrm{H}(10)]$. Although it had been previously demonstrated ${ }^{49}$ that the hydrogens of the aromatic ring are the major sites for the interactions of the anions, our previous results ${ }^{2}$ and the data obtained in the current work point toward a more complex situation. Indeed, in the presence of a salting-in-inducing ion, additional ion binding occurs between the hydrophobic alkyl chain moiety of the IL cation and the anion, as shown by the positive deviations observed for protons $\mathrm{H}(7), \mathrm{H}(8)$, and $\mathrm{H}(9)$ depicted in Figure 7, which are the consequence of attractive interactions between $\mathrm{SCN}^{-}$and the protons of the larger side alkyl chain of the IL. These favorable interactions are absent in the case of the salting-out-inducing ion $\mathrm{SO}_{4}{ }^{2-}$, as can be seen in Figure 6. In the case of $\mathrm{NaCl}, \mathrm{H}(8)$ and $\mathrm{H}(9)$ dictate the interactions established. For a nearly critical composition of the IL (Figure $5 \mathrm{~b}$ ), these are practically nonexistent and become less favorable as the molality of the inorganic species increases. This is in good agreement with the LLE results presented in Figures $2 \mathrm{~b}$ and 3 for $\left[\mathrm{C}_{4} \mathrm{mim}\right]\left[\mathrm{C}(\mathrm{CN})_{3}\right]$ and with LLE data obtained for $\left[\mathrm{C}_{4} \mathrm{mim}\right]\left[\mathrm{BF}_{4}\right]^{42}$ but are in stark contrast to what was previously observed for $\left[\mathrm{C}_{4} \mathrm{mim}\right]\left[\mathrm{TF}_{2} \mathrm{~N}\right]$ at low concentrations of $\mathrm{NaCl}$, where salting-in takes place. ${ }^{1,2}$ This topic will be analyzed in more detail in the discussion below. For a lower mole fraction of the IL (Figure 5a), the slightly positive deviations detected for $\mathrm{H}(8)$ and $\mathrm{H}(9)$ at low $\mathrm{Cl}^{-}$concentrations support the salting-in phenomena observed in Figure 2a at nearly $w_{\mathrm{IL}}=0.1$. At higher IL concentrations, and near the IL critical composition, the salting-out-inducing behavior is more evident (Figure 2). Results from Figure $5 \mathrm{~b}$ are in total agreement with LLE experimental results where the nonfavorable interactions are dominant for all the IL cation structure. Therefore, these results show the trend observed before ${ }^{1}$ for the $\left[\mathrm{C}_{4} \operatorname{mim}\right]\left[\mathrm{Tf}_{2} \mathrm{~N}\right]$ solubility in water in the presence of $\mathrm{NaCl}$ : IL salting-in at low salt concentrations followed by the IL salting-out at significant salt concentrations.

From the arguments presented so far, it can be perceived that the results obtained for the solubility behavior of aqueous saline solutions of $\left[\mathrm{C}_{4} \mathrm{mim}\right]\left[\mathrm{C}(\mathrm{CN})_{3}\right]$ support the mechanisms proposed for the action of salting-in- and salting-out-inducing ions in aqueous solutions of ILs. ${ }^{1,2}$ In particular, the NMR spectroscopic data constitutes further evidence for the direct binding of saltingin-inducing ions to the hydrophobic moiety of the IL cation, the mechanism by which the former are thought to operate in aqueous saline mixtures of ILs. Nevertheless, the comparison of the data gathered in the current work with those obtained before ${ }^{1,2,42}$ makes it possible to go deeper in the interpretation of the solubility effects, allowing a more detailed description of the phenomena occurring in these systems. In fact, when comparing the data available for three $\left[\mathrm{C}_{4} \mathrm{mim}\right]$-based ILs $\left(\left[\mathrm{Tf}_{2} \mathrm{~N}\right],{ }^{1,2}\left[\mathrm{BF}_{4}\right],{ }^{42}\right.$ and $\left[\mathrm{C}(\mathrm{CN})_{3}\right]$ (current work)), two major aspects are worth noting: (i) $\mathrm{Cl}^{-}$promotes a salting-out effect in $\left(\left[\mathrm{C}_{4} \mathrm{mim}\right]\left[\mathrm{BF}_{4}\right]+\right.$ water $)$ systems, but slightly salting-in followed by salting-out in $\left(\left[\mathrm{C}_{4} \mathrm{mim}\right]\left[\mathrm{Tf}_{2} \mathrm{~N}\right]+\right.$ water $)$ and in $\left(\left[\mathrm{C}_{4} \mathrm{mim}\right]\left[\mathrm{C}(\mathrm{CN})_{3}\right]+\right.$ water) mixtures; (ii) $\mathrm{NO}_{3}{ }^{-}$has a practically negligible solubility effect in aqueous solutions of $\left[\mathrm{C}_{4} \mathrm{mim}\right]\left[\mathrm{C}(\mathrm{CN})_{3}\right]$ but has a pronounced salting-in-inducing behavior in the case of $\left[\mathrm{C}_{4} \mathrm{mim}\right]\left[\mathrm{Tf}_{2} \mathrm{~N}\right]{ }^{1,2}$ Since the systems under comparison only differ in the IL anion, it is reasonable to infer that the interactions of the anion of the IL with the anion of the salt are quite important and will have a determinant role on the mechanism by which the inorganic species influence the aqueous solubility of the ionic liquid. The interactions of the salt anion will thus be established both with the cation and with the anion of the IL, and the consequent solubility effect will result from the balance of those two interactions. Since these have both a dispersive and an electrostatic character, the type of dominant interaction will depend on the nature (charge and size) both of the anion of the IL and of the anion of the salt. Therefore, when the anion of the IL becomes smaller and its charge more localized, as it happens sequentially from $\left[\mathrm{C}_{4} \mathrm{mim}\right]\left[\mathrm{Tf}{ }_{2} \mathrm{~N}\right]$ to $\left[\mathrm{C}_{4} \mathrm{mim}\right]\left[\mathrm{C}(\mathrm{CN})_{3}\right]$ and to $\left[\mathrm{C}_{4} \mathrm{mim}\right]\left[\mathrm{BF}_{4}\right]$, the dispersive character of the interactions established with the inorganic species becomes less important, and electrostatic repulsions start to dominate the scenario. High charged density ions such as $\mathrm{Cl}^{-}$that establish almost nonsignificant (predominantly dispersive) interactions with $\mathrm{Tf}_{2} \mathrm{~N}^{-}$, start thus to experience unfavorable interactions with $\mathrm{C}(\mathrm{CN})_{3}{ }^{-}$and even more unfavorable interactions with $\mathrm{BF}_{4}^{-}$, due to the electrostatic repulsive character of the forces originated. As a consequence, $\mathrm{Cl}^{-}$has a less pronounced effect on aqueous solutions of $\left[\mathrm{C}_{4} \mathrm{mim}\right]\left[\mathrm{Tf}_{2} \mathrm{~N}\right]$ and a more pronounced salting-out effect on water mixtures of the other two ILs, since it excludes itself from the vicinity of the latter due to its preferential hydration. Following this reasoning, it is fair to suppose that the saltingout effect induced by $\mathrm{Cl}^{-}$on $\left[\mathrm{C}_{4} \mathrm{mim}\right]\left[\mathrm{BF}_{4}\right]$ solutions is even more accentuated than on $\left(\left[\mathrm{C}_{4} \mathrm{mim}\right]\left[\mathrm{C}(\mathrm{CN})_{3}\right]+\right.$ water $)$ systems, although we do not dispose of enough data to support this statement. For its turn, larger inorganic anions with disperse charges such as $\mathrm{NO}_{3}{ }^{-}$will be able to originate dispersive interactions with $\mathrm{Tf}_{2} \mathrm{~N}^{-}$, being the result a noticeable saltingout effect; with $\mathrm{C}(\mathrm{CN})_{3}{ }^{-}$; however, the interactions established will be unfavorable and actually more unfavorable than in the case of $\mathrm{Cl}^{-}$since the electrostatic repulsions are even more important. The result is a practically negligible solubility effect on aqueous solutions of $\left[\mathrm{C}_{4} \mathrm{mim}\right]\left[\mathrm{C}(\mathrm{CN})_{3}\right]$. In spite of the absence of data available for aqueous nitrate solutions of $\left[\mathrm{C}_{4} \mathrm{mim}\right]\left[\mathrm{BF}_{4}\right]$, it is reasonable to conjecture that $\mathrm{NO}_{3}{ }^{-}$will have a similar or even less pronounced solubility effect.

To conclude, the data available seem to indicate that $\mathrm{Cl}^{-}$(and other anions with the same charge/size relation) will have a practically negligible solubility effect in aqueous solutions of 
$\left[\mathrm{C}_{4} \mathrm{mim}\right]$-based ILs comprising large anions with disperse charges, representing therefore in those cases the zero of the rank of the Hofmeister series, and that $\mathrm{NO}_{3}{ }^{-}$(and other anions with similar structures) an equally almost unimportant solubilityinducing behavior on aqueous mixtures of [ $\left.\mathrm{C}_{4} \mathrm{mim}\right]$-based ILs containing small and high charged anions in their constitution. Unfortunately, getting information on interactions with nonhydrogenated fluorinated anions or with $\mathrm{C}(\mathrm{CN})_{3}{ }^{-}$is not an easy task, but the use of hydrogenated anions will be the object of a future work to further elucidate those type of interactions.

Both thermodynamic and spectroscopic data gathered in this study constitute further evidence for the mechanisms of action proposed for salting-in- and salting-out-inducing ions in water + ILs mixtures. ${ }^{1,2}$ Liquid-liquid equilibrium results provide experimental evidence for the model suggested by Zhang et al. ${ }^{25}$ supporting the salting-out phenomenon, whereas ${ }^{1} \mathrm{H}$ NMR data enable a clearer picture of the salting-in phenomena, corroborating the conclusion ${ }^{2}$ that the solubility of ILs in water is essentially controlled by the specific interactions of the salt ions with the IL hydrophobic moiety. The comparison between different ( $\left[\mathrm{C}_{4} \mathrm{mim}\right]$-based ILs + water) systems enables a more detailed description of the mechanisms and suggests that the interactions of the inorganic species are not only established at the level of the IL cation, but also at its anion.

\section{Conclusion}

Further experimental evidence for the molecular-level mechanisms that dictate the behavior of aqueous saline solutions of ILs are provided in this work. The influence of inorganic anions on the liquid-liquid behavior of $\left[\mathrm{C}_{4} \mathrm{mim}\right]\left[\mathrm{C}(\mathrm{CN})_{3}\right]+$ water qualitatively follows the Hofmeister series, as verified for other charged molecules such as proteins. The salting-out and saltingin effects observed are dependent on the nature and concentration of the ions and can be understood in terms of direct or indirect (water-mediated) interactions between the anions and the solute, and not on the basis of changes in bulk water structure promoted by the inorganic species. The microscopic nature of the salting-out and salting-in phenomena is essentially different, with the former being the result of the tendency of high charge density ions to form water-ion hydration complexes that cause the dehydration of the solute and the increase of the surface tension of the cavity (an entropically driven effect), and the latter is a consequence of the direct binding of the anion to the hydrophobic moiety of the solute. This does not occur for salting-out-inducing ions since their binding with water molecules is preferential.

Together with data available for other $\left[\mathrm{C}_{4} \mathrm{mim}\right]$-based ILs aqueous systems, the results gathered in this work provided a deeper molecular-level understanding of the solubility behavior of aqueous IL saline solutions, suggesting that the interactions of the anion of the salt are not only established with the IL cation but also with its anion, with the observed solubility effect the consequence of a balance between those.

From a practical point of view, the results presented in the current study are also relevant for development and further research in the domains of separation technology. Inorganic species such as carbonates, sulfates and, to a lesser extent, chlorides, may be used to promote salting-out effects in aqueous solutions containing ILs, offering the possibility of improving the efficiency of liquid-liquid extraction processes of biological molecules and the development of new aqueous biphasic systems.

Once extrapolated to other charged or uncharged molecules rather than ILs, the conclusions taken from this work can be helpful in the interpretation of the solubility phenomena occurring in a wide range of aqueous systems.

Acknowledgment. The authors thank financial support from Fundação para a Ciência e a Tecnologia for Project PTDC/EQUFTT/65252/2006 and post-doctoral grant SFRH/BPD/41781/ 2007 of Mara G. Freire. The authors are also grateful to Catarina M. S. S. Neves for the help with the ${ }^{1} \mathrm{H}$ NMR spectra.

Supporting Information Available: This material is available free of charge via the Internet at http://pubs.acs.org.

\section{References and Notes}

(1) Freire, M. G.; Carvalho, P. J.; Silva, A. M. S.; Santos, L. M. N. B. F.; Rebelo, L. P. N.; Marrucho, I. M.; Coutinho, J. A. P. J. Phvs. Chem. B, 2009, 113, 202.

(2) Freire, M. G.; Neves, C. M. S. S.; Silva, A. M. S.; Santos, L. M. N. B. F.; Rebelo, L. P. N.; Marrucho, I. M.; Shah, J. K.; Maggin, E. J.; Coutinho, J. A. P. J. Phys. Chem. B, 2008, submitted.

(3) MacFarlane, D. R.; Seddon, K. R. Aust. J. Chem. 2007, 60, 3.

(4) Earle, M. J.; Esperança, J. M. S. S.; Gilea, M. A.; Canongia Lopes, J. N.; Rebelo, L. P. N.; Magee, J. W.; Seddon, K. R.; Widegren, J. A. Nature 2006, 439, 831.

(5) Welton, T. Chem. Rev. 1999, 99, 2071.

(6) Earle, M. J.; Seddon, K. R. Pure Appl. Chem. 2000, 72, 1391.

(7) Brennecke, J. F.; Maginn, E. J AIChE J. 2001, 47, 2384.

(8) Freemantle, M. Chem. Eng. News 2007, 85, 23.

(9) Dai, S.; Ju, Y. H.; Barnes, C. E. J. Chem. Soc. Dalton Trans. 1999, 1201.

(10) Smirnova, V. S.; Torocheshnikova, I. I.; Formanovsky, A. A.; Pletnev, I. V. Anal. Bioanal. Chem. 2004, 378, 1369.

(11) Wu, C.-T.; Marsh, K. N.; Deev, A. V.; Boxall, J. A. J. Chem. Eng. Data 2003, 48, 486.

(12) Huddleston, J. G.; Willauer, H. D.; Swatloski, R. P.; Visser, A. E.; Rogers, R. D. Chem. Commun. 1998, 16, 1765.

(13) Fadeev, A. G.; Meagher, M. M. Chem. Commun. 2001, 295

(14) McFarlane, J.; Ridenour, W. B.; Luo, H.; Hunt, R. D.; DePaoli,

D. W.; Ren, R. X. Sep. Sci. Technol. 2005, 40, 1245.

(15) Freire, M. G.; Carvalho, P. J.; Gardas, R. L.; Marrucho, I. M.; Santos, L. M. N. B. F.; Coutinho, J. A. P. J. Phys. Chem. B 2008, 112, 1604.

(16) Freire, M. G.; Neves, C. M. S. S.; Carvalho, P. J.; Gardas, R. L.; Fernandes, A. M.; Marrucho, I. M.; Santos, L. M. N. B. F.; Coutinho, J. A. P. J. Phvs. Chem. B 2007, 111, 13082.

(17) Freire, M. G.; Santos, L. M. N. B. F.; Fernandes, A. M.; Coutinho, J. A. P.; Marrucho, I. M. Fluid Phase Equilib. 2007, 261, 449.

(18) Najdanovic-Visak, V.; Esperança, J. M. S. S.; Rebelo, L. P. N.; Ponte, M. N.; Guedes, H. J. R.; Seddon, K. R.; Szydlowski, J. Phvs. Chem. Chem. Phvs. 2002, 4, 1701.

(19) Domanska, U.; Marciniak, A. Fluid Phase Equilib. 2007, 260, 9. (20) Kunz, W.; Henle, J.; Ninham, B. W. Curr. Opin. Colloid Interface Sci. 2004, 9, 19.

(21) Hofmeister, F. Arch. Exp. Pathol. Pharmakol. 1888, 24, 247.

(22) Kunz, W.; Lo Nostro, P.; Ninham, B. W. Curr. Opin. Colloid Interface Sci. 2004, 9, 1.

(23) Collins, K. D.; Washabaugh, M. W. Q. Rev. Biophvs. 1985, 18, 323.

(24) Baldwin, R. L. Biophvs. J. 1996, 71, 2056.

(25) Zhang, Y. J.; Furyk, S.; Bergbreiter, D. E.; Cremer, P. S. J. Am. Chem. Soc. 2005, 127, 14505.

(26) Bauduin, P.; Nohmie, F.; Touraud, D.; Neueder, R.; Kunz, W.; Ninham, B. W. J. Mol. Liq. 2006, 123, 14.

(27) Omta, A. W.; Kropman, M. F.; Woutersen, S.; Bakker, H. J. Science 2003, 301, 347.

(28) Batchelor, J. D.; Olteanu, A.; Tripathy, A.; Pielak, G. J. $\underline{\text { J. Am. }}$ Chem. Soc. 2004, 126, 1958.

(29) Gurau, M. C.; Lim, S. M.; Castellana, E. T.; Albertorio, F.; Kataoka, S.; Cremer, P. S. J. Am. Chem. Soc. 2004, 126, 10522.

(30) Bostrom, M.; Williams, D. R. M.; Ninham, B. W. Phvs. Rev. Lett. 2001, 87, 347.

(31) Zhang, Y.; Cremer, P. S. Curr. Opin. Chem. Biol. 2006, 10, 658. (32) Zou, Q.; Bennion, B. J.; Daggett, V.; Murphy, K. P. J. Am. Chem. Soc. 2002, 124, 1192.

(33) Vanzi, F.; Madan, B.; Sharp, K. J. Am. Chem. Soc. 1998, 120, 10748.

(34) Washabaugh, M. W. Q.; Collins, K. D. J. Biol. Chem. 1986, 261, 2477.

(35) Koga, Y.; Westh, P.; Davies, J. V.; Miki, K.; Mishikawa, K.; Katayanagi, H. J. Phvs. Chem. A 2004, 108, 8533. 
(36) Koga, Y.; Katayanagi, H.; Davies, J. V.; Kato, H.; Nishikawa, K.; Westh, P. Bull. Chem. Soc. Jpn. 2006, 79, 1347.

(37) Westh, P.; Kato, H.; Nishikawa, K.; Koga, Y. J. Phvs. Chem. A 2006, 110, 2072.

(38) Bostrom, M.; Williams, D. R. M.; Ninham, B. W. Biophys. J. 2003, 85,686 .

(39) Bostrom, M.; Williams, D. R. M.; Ninham, B. W. Phys. Rev. Lett. 2001, 87,168103 .

(40) Zhang, Y.; Furyk, S.; Bergbreiter, D. E.; Cremer, P. S. J. Am. Chem. Soc. 2005, 127, 14505 .

(41) Zhang, Y.; Furyk, S.; Sagle, L. B.; Cho, Y.; Bergbreiter, D. E.; Cremer, P. S. J. Phvs. Chem. C 2007, 111, 8916.

(42) Trindade, J. R.; Visak, Z. P.; Blesic, M.; Marrucho, I. M.; Coutinho, J. A. P.; Lopes, J. N. C.; Rebelo, L. P. N. J. Phvs. Chem. B 2007, 111, 4737.
(43) Kalra, A.; Tugcu, N.; Cramer, S. M.; Garde, S. J. Phvs. Chem. B 2001, 105, 6380.

(44) Holz, M. J. Mol. Liq. 1995, 67, 175

(45) Zangi, R.; Hagen, M.; Berne, B. J. Am. Chem. Soc. 2007, 129, 4678 .

(46) Zangi, R.; Berne, B. J. Phys. Chem. B 2006, 110, 22736.

(47) Marcus, Y. Ion Properties; Marcus Dekker, Inc: New York, 1997.

(48) International Critical Tables of Numerical Data, Physics, Chemistry and Technology, 1st ed.; MacGraw-Hill: New York, 1928; Vol. IV.

(49) Bonhôte, P.; Dias, A. P.; Papageorgiou, N.; Kalyanasundaram, K.; Gratzel, M. Inorg. Chem. 1996, 35, 1168.

JP810141D 